\title{
Rehabilitation cost share and cost analysis of traumatic hand injuries: Our single-center results
}

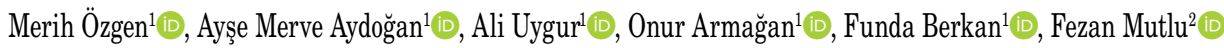 \\ ${ }^{1}$ Department of Physical Medicine and Rehabilitation, Eskișehir Osmangazi University, Faculty of Medicine, Eskisehir, Turkey \\ ${ }^{2}$ Department of Biostatistics and Medical Informatics, Eskişehir Osmangazi University, Faculty of Medicine, Eskisehir, Turkey
}

Received: October 25, 2019 Accepted: May 03, 2020 Published online: September 01, 2021

\begin{abstract}
Objectives: This study aims to evaluate the cost expenses and rehabilitation share of hand and/or wrist injuries and to contribute to the development of health and economic policies.

Patients and methods: A total of 59 patients (55 males, 4 females; mean age: $39.1 \pm 11.3$ years; range, 20 to 64 years) who presented with hand and/or wrist injuries between January 2015 and December 2017 were retrospectively reviewed. Demographic data, hand injury information, and the Modified Hand Injury Severity Scores (MHISS) were retrieved from the patient file system. The cost analysis with direct and indirect costs was performed.
\end{abstract}

Results: According to the MHISS, $27.1 \%$ of patients had a minor injury, 23.7\% had a moderate injury, $18.6 \%$ had a severe injury, and $30.5 \%$ had a major injury. The mean direct cost of the patients was $\$ 726.00 \pm 641.87$ and the total cost of the indirect cost was $\$ 2,776.93 \pm 1,619.00$. The mean day-off time was $125 \pm 68.62$ days. Indirect costs accounted for $79 \%$ of the total cost. The mean cost of rehabilitation was $\$ 150.18 \pm 86.88$. Rehabilitation costs accounted for $4 \%$ of the total cost. There was a positive correlation between the MHISS and direct, indirect and total cost, but not between the MHISS and rehabilitation cost.

Conclusion: The proportion of the share allocated to rehabilitation expenditures, which is the subunit of direct cost, is low and not related to the injury severity. The data obtained from the study contributed to the creation of evidence-based health and economic policies. We believe that these data also contribute to the planning of rehabilitation services according to the severity of injury which would improve the quality of life and return to work.

Keywords: Costs, cost analysis, hand injuries, rehabilitation.

Hand and wrist injuries are common in the community, accounting for $20 \%$ of all emergency department admissions. ${ }^{[1]}$ It causes more cost than knee, hip and head trauma according to the intensity of injuries occurring each year. ${ }^{[2]}$ Hand injuries are usually seen in males under the age of 40 years and usually occur due to work, home, traffic, hobby, and sports injuries. ${ }^{[3]}$

There is a wide range of hand and wrist injuries including simple soft tissue injuries, complicated wounds, tendon and nerve injuries, fractures, and amputations. Injuries can be mainly classified as minor, moderate, severe, and major according to their severity ${ }^{[4]}$ According to the severity of injury, some patients return to their former functions, while some others require a long-term rehabilitation and recovery. In some of these patients, disability may develop. ${ }^{[1]}$

Hand and/or wrist injuries are the injuries that have a high risk of causing morbidity, as they affect the functionality. In addition, the diagnosis of hand injuries can be overlooked in the emergency department and, thus, even minor injuries can lead to chronic problems and impair the function. ${ }^{[5]}$ Injuries to the hands and forearms are the causes of serious economic problems

\footnotetext{
Corresponding author: Merih Özgen, MD. Eskişehir Osmangazi Üniversitesi Tıp Fakültesi Fiziksel Tip ve Rehabilitasyon Anabilim Dalı, 26040 Meşelik, Eskişehir, Türkiye. e-mail: merihsarhus@hotmail.com 
for both the individual and the society, leading to high costs and long-term sick leave. ${ }^{[6]}$

Due to the increasing health costs in recent years, economic analyses in the field of health have become increasingly important. ${ }^{[7]}$ Cost of illness is the sum of direct, indirect, and intangible costs associated with the disease. Direct costs are medical costs (i.e., surgical treatment, inpatient treatment, drugs, laboratory, postoperative care, or rehabilitation services) and non-medical costs (such as transportation to medical facilities). Indirect costs are usually paid by the individual, family, community and employer, and are related to morbidity and mortality. Indirect costs are more difficult to calculate than direct costs. Intangible costs are non-monetary costs due to functional limitations, pain, psychological distress, and reduced

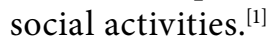

In the literature, there is a limited number of studies examining the cost of hand and/or wrist injuries in which methodological differences are present. Previous studies have shown that the cost associated with long-term job losses is higher than health care costs. ${ }^{[8]}$ Injuries to the upper extremity result in economic losses and cause more serious consequences, particularly in the industrial area. ${ }^{[9,10]}$ Although the cost studies related to hand and/or wrist injuries are available in the literature, there is no study investigating the rehabilitation cost ratio. In the present study, we, therefore, aimed to evaluate the cost expenses and rehabilitation share of hand and/or wrist injuries and to contribute to the development of health and economic policies.

\section{PATIENTS AND METHODS}

This single-center, retrospective study was conducted at Eskişehir Osmangazi University, Faculty of Medicine, Department of Physical Medicine and Rehabilitation between January 2015 and December 2017. A total of 191 patients with isolated hand and/or wrist injuries who were admitted to our outpatient clinic were screened. Of these, 105 who did not receive the rehabilitation program in our clinic, 22 in whom the loss of labor force could not be estimated (i.e., housewife, retired, or student), and five with multiple body injuries were excluded. Finally, a total of 59 patients ( 55 males, 4 females; mean age: $39.1 \pm 11.3$ years; range, 20 to 64 years) were included in the study. The study flow chart is shown in Figure 1. A written informed consent was obtained from each patient. The study protocol was approved by the Eskişehir Osmangazi University, Faculty of Medicine Ethics Committee (25403353-050.99-E.37666). The study was conducted in accordance with the principles of the Declaration of Helsinki.

Medical records and invoices of the patients included in the study were examined. Age, sex, occupational, and injury data of the patients (i.e., injured hand, injury type, accident type, injury-causing body, and lesion type) and the Modified Hand Injury Severity Score (MHISS) were obtained from the patient file system. Data obtained from the patient files were as follows: occupation (desk, worker, other), injured hand (right, left), type of injury (accident, intentional) type of accident (home accidents, work accidents, traffic accidents), objects causing injury (cutting object,
191 patients with hand/wrist injuries were retrospectively reviewed

\section{Excluded}

105 patients received orthopedic rehabilitation program in other clinics

Work force loss of 22 patients could not be calculated (retired, student, unemployed etc.)

Five patients had multiple body injuries

59 patients included in the study

Figure 1. Study flow chart. 
machine, heavy object, spiral saw, traffic, fall/other type of injury and injuries (isolated flexor tendon injury, isolated extensor tendon injury, fracture, amputation, isolated nerve injury, flexor tendon injury and nerve injuries at the wrist level, flexor tendon injury and distal nerve at the wrist injuries, fractures and tendon injuries).

The MHISS was used to assess the level of injury severity. This scoring system was first developed by Campbell and $\mathrm{Kay}^{[4]}$ as the Hand Injury Severity Scoring (HISS) to evaluate the skin, skeletal, motor and nerve tissues of the hand and carpal region. Urso-Baiarda et al. ${ }^{[1]}$ developed the MHISS by modifying HISS to evaluate hand, wrist, and forearm injuries. The score ranges from 1 to 100 . Using the MHISS, hand injuries are evaluated in four main categories as minor, moderate, severe, and major (minor MHISS <20, moderate MHISS 21-50, severe MHISS 51-100, major MHISS >100). Higher scores indicate a greater injury severity.

\section{Cost analysis}

Cost analysis was calculated as direct and indirect cost analysis in two ways. In the calculation of the health expenditures of the patients, the amounts billed to the Social Security Institution (SGK) were recorded by using our Faculty of Medicine Hospital Information Management System (HIMS).

Direct costs were analyzed as the total cost of physical therapy (i.e., number of outpatient visits,

\begin{tabular}{|c|c|c|}
\hline \multicolumn{3}{|c|}{$\begin{array}{c}\text { TABLE } 1 \\
\text { Baseline demographic characteristics of patients and } \\
\text { injury types }\end{array}$} \\
\hline & $\mathrm{n}$ & $\%$ \\
\hline \multicolumn{3}{|l|}{ Sex } \\
\hline Male & 55 & 93.2 \\
\hline Female & 4 & 6.8 \\
\hline \multicolumn{3}{|l|}{ Job } \\
\hline Desk work & 6 & 10.2 \\
\hline Hand work & 53.6 & 89.8 \\
\hline \multicolumn{3}{|l|}{ Injured hand } \\
\hline Right & 26 & 44.1 \\
\hline Left & 33 & 55.9 \\
\hline \multicolumn{3}{|l|}{ Type of injury } \\
\hline Accident & 56 & 94.9 \\
\hline Intentional injury & 3 & 5.1 \\
\hline \multicolumn{3}{|l|}{ Accident type } \\
\hline Home & 41 & 69.5 \\
\hline Work & 17 & 28.8 \\
\hline Traffic & 1 & 1.7 \\
\hline
\end{tabular}

number of rehabilitation sessions and cost of rehabilitation) and all other hospital costs (i.e., surgical outpatient applications, surgery, material use, anesthesia, laboratory tests, radiological imaging, hospitalization days, drugs during hospitalization, and consultation services).

Indirect costs were calculated based on the minimum wage determined by the state during the year in which the patient was not injured due to injury. In this period, the sum of the amounts paid by the SGK per patient on the day of sick leave was added to the indirect cost analysis. The sum of the amounts paid by the SGK per patient per day was added to the indirect costs. To make a comparison with the global data, the cost calculations were converted into United States (US) Dollars by the Central Bank's three-year exchange rate average between 2015 and 2017.

\section{Statistical analysis}

The statistical analyses were performed using IBM SPSS version 22.0 (IBM Corp., Armonk, NY, USA). Continuous variables were expressed in mean \pm standard deviation (SD). Continuous variables are assessed using the Shapiro Wilk test. The Spearman correlation analysis was used to investigate the relationship between the variables. The categorical variables are expressed in frequencies and percentages. A $p$ value of $<0.05$ was considered statistically significant.

\section{RESULTS}

Baseline demographic characteristics of the patients and injury types are shown in Table 1.

The causes of hand and/or wrist injuries of patients are given in Table 2 and the distribution of injuries according to lesion type is given in Table 3.

The distribution of hand and/or wrist injuries according to the MHISS was minor in 16 (21\%),

\begin{tabular}{|lcc|}
\multicolumn{4}{c|}{ TABLE 2 } \\
Causes of hand and/or wrist injury & \\
\hline Cutter body & $\mathrm{n}$ & $\%$ \\
Machine & 26 & 44.1 \\
Heavy object & 18 & 30.5 \\
Spiral saw & 10 & 16.9 \\
Traffic & 3 & 5.1 \\
Other/fall & 1 & 1.7 \\
\hline
\end{tabular}




\begin{tabular}{|c|c|c|}
\hline \multicolumn{3}{|c|}{$\begin{array}{c}\text { TABLE } 3 \\
\text { Distribution of hand and/or wrist injuries according to } \\
\text { lesion type }\end{array}$} \\
\hline & $\mathrm{n}$ & $\%$ \\
\hline Extender tendon injury & 12 & 20.34 \\
\hline Flexor tendon injury & 9 & 15.25 \\
\hline Fracture & 7 & 11.86 \\
\hline Amputation & 13 & 22.03 \\
\hline Isolated nerve injury & 1 & 1.70 \\
\hline $\begin{array}{l}\text { Main nerve injury at wrist level and } \\
\text { flexor tendon injury }\end{array}$ & 7 & 11.86 \\
\hline Flexor tendon and digital nerve injury & 3 & 5.09 \\
\hline Fracture and tendon injury & 7 & 11.86 \\
\hline Total & 59 & 100.00 \\
\hline
\end{tabular}

moderate in 14 (23.7\%), severe in $11(18.6 \%)$, and major in $18(18 \%)$ of the patients. The mean duration of sick leave due to injury was $125.3 \pm 68.6$ (range, 30 to 335 ) days. The mean number of rehabilitation sessions for the hand and/or wrist injuries was $20.3 \pm 9$ (range, 2 to 30 ). The direct, indirect, and total cost analyses of the patients were calculated in the Turkish Lira and US Dollar (Table 4). Accordingly, $79 \%$ of the total cost was indirect cost and $21 \%$ was

\begin{tabular}{|lc|}
\multicolumn{2}{|c|}{ TABLE 4 } \\
\multicolumn{2}{|c|}{ Cost analysis of hand and/or wrist injuries } \\
\hline & Mean \pm SD \\
\hline Rehabilitation cost (\$) & $150.18 \pm 86.88$ \\
Direct cost (\$) & $726.00 \pm 641.87$ \\
Indirect cost (\$) & $2,776.93 \pm 1,619.00$ \\
Total cost $(\$)$ & $3,502.94 \pm 1,951.85$ \\
\hline SD: Standard deviation. & \\
\hline
\end{tabular}

direct cost. The cost of rehabilitation accounted for $4 \%$ of the total cost.

The correlation analysis revealed a positive correlation between the MHISS and number of session and cost (direct, indirect, total). Rehabilitation services and the number of rehabilitation sessions performed were also positively correlated with the total cost, but not with the MHISS (Table 5).

\section{DISCUSSION}

In the present study, we evaluated the cost of hand and/or wrist injuries and the rehabilitation share among these expenses. We found that the mean direct cost was $\$ 726.00 \pm 641.87$, the mean indirect cost was $\$ 2,776.93 \pm 1,619.00$, and the mean total cost was

\begin{tabular}{|c|c|c|c|c|c|c|c|}
\hline & & & earman corre & $\begin{array}{l}\text { BLE } 5 \\
\text { ation analy }\end{array}$ & s results & & \\
\hline & MHISS & Sick leave & Indirect cost & Direct cost & Total cost & Rehabilitation cost & Number of sessions \\
\hline MHI & & & & & & & \\
\hline $\mathrm{r}$ & - & 0.343 & 0.307 & 0.665 & 0.471 & 0.222 & 0.253 \\
\hline$p$ & - & 0.008 & 0.018 & $<0.001$ & $<0.001$ & 0.091 & 0.053 \\
\hline Sick & & & & & & & \\
\hline $\mathrm{r}$ & 0.343 & - & 0.683 & 0.171 & 0.920 & 0.219 & 0.249 \\
\hline$p$ & 0.008 & - & $<0.001$ & 0.196 & $<0.001$ & 0.96 & 0.057 \\
\hline Indir & & & & & & & \\
\hline $\mathrm{r}$ & 0.307 & 0.972 & - & -0.111 & 0.947 & 0.247 & 0.275 \\
\hline$p$ & 0.018 & $<0.001$ & - & 0.402 & $<0.001$ & 0.059 & 0.035 \\
\hline Dire & & & & & & & \\
\hline $\mathrm{r}$ & 0.665 & 0.019 & 0.171 & - & 0.439 & 0.507 & 0.518 \\
\hline$p$ & $<0.001$ & 0.888 & 0.196 & - & 0.001 & $<0.001$ & $<0.001$ \\
\hline Total & & & & & & & \\
\hline $\mathrm{r}$ & 0.471 & 0.884 & 0,920 & 0.439 & - & 0.415 & 0.433 \\
\hline$p$ & $<0.001$ & $<0.001$ & $<0.001$ & 0.001 & - & 0.001 & 0.001 \\
\hline Reha & & & & & & & \\
\hline $\mathrm{r}$ & 0.222 & 0.219 & 0.216 & 0.507 & 0.390 & - & 0.949 \\
\hline$p$ & 0.091 & 0.96 & 0.100 & $<0.001$ & 0.002 & - & $<0.001$ \\
\hline Num & & & & & & & \\
\hline $\mathrm{r}$ & 0.253 & 0.249 & 0.180 & 0.470 & 0.433 & 0.949 & - \\
\hline$p$ & 0.053 & 0.057 & 0.172 & $<0.001$ & 0.001 & $<0.001$ & - \\
\hline
\end{tabular}


$\$ 3,502.94 \pm 1,951.85$. The mean cost of rehabilitation was $\$ 471.58 \pm 272.81$ total / $\$ 150.18 \pm 86.88$, accounting for $4 \%$ of the total cost. With the increase of MHISS, direct, indirect and total costs increased and there was no change in the cost of rehabilitation.

Hand and wrist injuries are a public health problem. Therefore, the negative effect of the increase in cost is observed not only in individuals, but also in national income. As each country has its own health policy, specific health expenses vary among countries. In their study, Robinson et al. ${ }^{[1]}$ reached 764 articles about hand and wrist injuries on OVID, AMED, EMBASE, CENTRAL, SCOPUS, CINHAL databases, and evaluated 21 eligible studies. In this review, the average total cost of hand and wrist injuries was $\$ 6,951$, the direct cost was $\$ 1,900.50$, and the indirect cost was $\$ 5,223$, representing $64 \%$ of the total cost. In a study conducted in Turkey by Şahin et al., ${ }^{[3]}$ the mean direct cost was $\$ 1,771.8 \pm 1,446.2$, the mean indirect cost was $\$ 3,370 \pm 2,623.3$, and the mean total cost was $\$ 5,141.9 \pm 3,417.3$. In another study, Oğuz et al. ${ }^{[12]}$ performed a direct cost analysis of 712 wrist and hand wrist injuries and reported a median cost per patient of $\$ 45.50$ (range, 16 to 5,131 ) with a total cost of $\$ 178,678.17$. Similar to the results of Robinson et al., ${ }^{[1]}$ in our study, the indirect cost accounted for $79 \%$ of the total cost.

In the literature, cost of rehabilitation has not been evaluated in previous cost-efficacy studies. Rehabilitation payments may vary according to the health and economic policies of each country. In our study, we found that the cost of rehabilitation was $4 \%$ of the total cost. To the best of our knowledge, our study is the first to emphasize the share of rehabilitation practices in the cost of traumatic hand and/or wrist injuries.

The MHISS scoring was developed by Urso-Baiarda et al., ${ }^{[11]}$ by updating the HISS scoring to include wrist and forearm injuries. In our study, we used the MHISS to evaluate the severity of injury.

It has been reported that the severity of injury affects the cost, leave time, long-term outcomes of rehabilitation, and return to work. ${ }^{[6,13-17]}$ The length of time to stay away from work after traumatic hand and/or wrist injuries varies according to the type and level of injury. ${ }^{[18]}$ There is a significant relationship between the HISS and recovery time. ${ }^{[19]}$ It has been shown that longer-term sick leave is used in relation to the size of the injury. ${ }^{[18]}$ In the literature, the average time to stay away from work has been reported to range from 30 days to 10 months..$^{[3,6,13,20,21]}$ In our study, the mean number of days of sick leave was 125.32 \pm 68.62 days. Consistent with the literature, the number of days of sick leave increased, as the severity of injury increased in our study.

The MHISS has been shown to be an important predictor of job return in hand and forearm injuries. ${ }^{[1]}$ Return to work is important for both the employee and the employer. For return to work, hand functions need to be improved at an advanced level. The main determinants of return to work are as follows: the level of physical and psychological well-being reached by the patient as a result of the treatment period; the characteristics of the job; expectations of the client; expectations of the patient; and the social and economic situation of the patient. Matsuzaki et al. ${ }^{[22]}$ reported that all patients with minor and moderate injuries were able to return to work, while $74 \%$ of severe injuries and only $29 \%$ of those with major injuries returned to their jobs. In the study of Şahin et al., ${ }^{[3]} 71 \%$ of the patients with hand and/or wrist injuries were able to return to work and $29 \%$ had to leave their work. In our study, the number of days with sick leave was evaluated. The number of days with sick leave increased in relation to the severity of injury. In our study, data were obtained from the patient file system within our institution. Since the SGK can cause ethical and legal problems, personal data were unable to be fully reached. Therefore, the duration of work return of the patients were unable to be evaluated.

Previous studies have shown a correlation between the cost and severity of injury. ${ }^{[3,6,17,23]}$ Rosberg et al. ${ }^{[6]}$ reported that the treatment period and costs of patients with hand and forearm major injuries were 10 times higher than those with minor injuries. There is no standard classification in the literature, and the cost of direct injury has been reported to be related to HISS. ${ }^{[1]}$ Şahin et al. ${ }^{[3]}$ found a correlation between the severity of injury, time to stay away from work, and direct cost in their study. They reported that the indirect cost was only correlated with the process of staying away from work. Rosberg et al. ${ }^{[6]}$ showed that the increased HISS scores were associated with the cost and duration of sick leave. Most of the total cost were generated by the share in production. In our study, direct, indirect, and total cost increased with the increase of the severity of injury, and indirect cost was the major part of the total cost. Although higher HISS leads to higher direct costs, this has no significant effect on total cost, which is a link between HISS and productivity loss; i.e., indirect costs. ${ }^{[1]}$ 
In the current study, the increase in direct costs did not cause an increase in the indirect cost, but the increase in the number of days with sick leave increased the indirect cost. Therefore, it is necessary to conduct further researches to reduce the indirect cost by facilitating return to work. Hand injuries need recovery and rehabilitation time, depending on the severity of injury. Hand injuries can result in long-term disabilities resulting in major economic problems. ${ }^{[2]}$ In our study, there was no significant relationship between MHISS and the number of rehabilitation sessions and the cost of rehabilitation. Although the total costs of the patients varied according to the type of lesion and severity of the injury, we considered the legal limitation (up to 30 sessions/year in one part/limb of the body) in the number of sessions of orthopedic rehabilitation as the reason for no significant difference in the rehabilitation costs. Considering the length of the number of days with sick leave, which is an indicator of disability, it is concluded that rehabilitation sessions, which are planned according to the severity of injury, increase the share allocated to rehabilitation, thereby reducing the incidence of disability, shortening the time to return, and reducing the total cost.

The most important step in cost management in hand and wrist injuries is to take the necessary measures to prevent injuries. We believe that having specialized hand physiotherapists and having a length of rehabilitation according to the severity score can reduce the cost. In addition, Sarkies et al. ${ }^{[25]}$ reported that health policies rarely included research evidence and, therefore, evidence-based policy and management decisions should be taken. It is recommended that future studies should follow the checklist of the Consolidated Health Economic Reporting Standards (CHEERS). ${ }^{[1,26]}$

In our study, there were no data about the time to return to work, change of job, or job position at the workplace. Therefore, direct and indirect costs were calculated using our database and the corresponding indirect costs. Since the cost of rehabilitation was derived from the records in our system, patients may have received treatment in external centers. The cost of services received in this way could not be included in these calculations. This is the main limitation of our study. On the contrary, the main strength of this study is that it is the first to evaluate the cost of rehabilitation services in traumatic hand and/or wrist injuries which can cause serious injuries.
In conclusion, this study is the first to emphasize the share of rehabilitation practices in the cost of traumatic hand and/or wrist injuries. Considering the length of the number of days with sick leave, which is an indicator of disability, we suggest that the number of rehabilitation sessions, which is planned according to the severity of injury, can reduce the total cost by accelerating the return of the patients to work and reducing the indirect costs and the loss of the workforce. Based on these findings, we believe that the data obtained from the study contribute to the development of evidence-based health and economic policies and to the planning of rehabilitation services according to the severity of the injury.

Declaration of conflicting interests

The authors declared no conflicts of interest with respect to the authorship and/or publication of this article.

Funding

The authors received no financial support for the research and/or authorship of this article.

\section{REFERENCES}

1. Robinson LS, Sarkies M, Brown T, O’Brien L. Direct, indirect and intangible costs of acute hand and wrist injuries: A systematic review. Injury 2016;47:2614-26.

2. de Putter CE, Selles RW, Polinder S, Panneman MJ, Hovius SE, van Beeck EF. Economic impact of hand and wrist injuries: health-care costs and productivity costs in a population-based study. J Bone Joint Surg [Am] 2012;94:e56.

3. Şahin F, Akca H, Akkaya N, Zincir ÖD, Işik A. Cost analysis and related factors in patients with traumatic hand injury. J Hand Surg Eur Vol 2013;38:673-9.

4. Campbell DA, Kay SP. The Hand Injury Severity Scoring System. J Hand Surg Br 1996;21:295-8.

5. Amsallem L, Pierrart J, Werthel JD, Delgrande D, Bihel T, Sekri J, et al. Hand injury without any deficit: Is systematic surgical exploration justified? Hand Surg Rehabil 2019;38:20-3.

6. Rosberg HE, Carlsson KS, Dahlin LB. Prospective study of patients with injuries to the hand and forearm: costs, function, and general health. Scand J Plast Reconstr Surg Hand Surg 2005;39:360-9.

7. Meerding WJ, Bonneux L, Polder JJ, Koopmanschap MA, van der Maas PJ. Demographic and epidemiological determinants of healthcare costs in Netherlands: cost of illness study. BMJ 1998;317:111-5.

8. Nilsen P, Hudson D, Lindqvist K. Economic analysis of injury prevention--applying results and methodologies from costof-injury studies. Int J Inj Contr Saf Promot 2006;13:7-13.

9. Jaquet JB, van der Jagt I, Kuypers PD, Schreuders TA, Kalmijn AR, Hovius SE. Spaghetti wrist trauma: functional recovery, return to work, and psychological effects. Plast Reconstr Surg 2005;115:1609-17.

10. Sanal HT. El ve el bileği kemik doku yaralanmaları: nedenler, işgücü kaybı. Gülhane Tıp Dergisi 2006;48:215-7. 
11. Urso-Baiarda F, Lyons RA, Laing JH, Brophy S, Wareham K, Camp D. A prospective evaluation of the Modified Hand Injury Severity Score in predicting return to work. Int J Surg 2008;6:45-50.

12. Oğuz AB, Polat $O$, Günalp $M$, Aygün $Z$, Genç S. Acil servise bașvuran el ve el bileği yaralanmalı hastaların maliyetlerinin incelenmesi. Ankara Üniversitesi Tip Fakültesi Mecmuası 2017;70:195-9.

13. Angermann $\mathrm{P}$, Lohmann M. Injuries to the hand and wrist. A study of 50,272 injuries. J Hand Surg Br 1993;18:642-4.

14. Hill C, Riaz M, Mozzam A, Brennen MD. A regional audit of hand and wrist injuries. A study of 4873 injuries. J Hand Surg Br 1998;23:196-200.

15. Chung KC, Spilson SVJT Johs. The frequency and epidemiology of hand and forearm fractures in the United States. 2001; 26: 908-15.

16. Bernstein ML, Chung KC. Hand fractures and their management: an international view. Injury 2006;37:1043-8.

17. Eriksson M, Karlsson J, Carlsson KS, Dahlin LB, Rosberg HE. Economic consequences of accidents to hands and forearms by log splitters and circular saws: cost of illness study. J Plast Surg Hand Surg 2011;45:28-34.

18. Rosberg HE, Carlsson KS, Cederlund RI, Ramel E, Dahlin LB. Costs and outcome for serious hand and arm injuries during the first year after trauma - a prospective study. BMC Public Health 2013;13:501.

19. van der Molen AB, Matloub HS, Dzwierzynski W, Sanger JR. The hand injury severity scoring system and workers' compensation cases in Wisconsin, USA. J Hand Surg Br 1999;24:184-6.
20. Mink van der Molen AB, Ettema AM, Hovius SE. Outcome of hand trauma: the hand injury severity scoring system (HISS) and subsequent impairment and disability. J Hand Surg Br 2003;28:295-9.

21. Çakır N, Özcan RH, Kitiş A, Büker N. Investigation of the relationship between severity of injury, return to work, impairment, and activity participation in hand and forearm injuries. Ulus Travma Acil Cerrahi Derg 2014;20:120-6.

22. Matsuzaki H, Narisawa H, Miwa H, Toishi S. Predicting functional recovery and return to work after mutilating hand injuries: usefulness of Campbell's Hand Injury Severity Score. J Hand Surg Am 2009;34:880-5.

23. Rosberg HE, Carlsson KS, Höjgård S, Lindgren B, Lundborg G, Dahlin LB. Injury to the human median and ulnar nerves in the forearm--analysis of costs for treatment and rehabilitation of 69 patients in southern Sweden. J Hand Surg Br 2005;30:35-9.

24. Rosenfield J, Paksima N. Peripheral nerve injuries and repair in the upper extremity. Bull Hosp Jt Dis 20012002;60:155-61.

25. Sarkies MN, Bowles KA, Skinner EH, Haas R, Lane H, Haines TP. The effectiveness of research implementation strategies for promoting evidence-informed policy and management decisions in healthcare: a systematic review. Implement Sci 2017;12:132.

26. Moran AE, Odden MC, Thanataveerat A, Tzong KY, Rasmussen PW, Guzman D, et 298 al. Cost-effectiveness of hypertension therapy according to 2014 guidelines. 2015; 299 372: 447-55. 